J. Nat. Hist. Mus. Vol. 30, 2016-18 121-128

\title{
Evidences of red panda in Rachuli VDC, Kalikot district, Nepal
}

\author{
Bishok Dangol ${ }^{1} \bowtie$ and Mukesh Kumar Chalise ${ }^{2}$ \\ ${ }^{1}$ Central Department of Enviornment Science, Tribhuvan University, Kirtipur, Kathmandu, Nepal \\ ${ }^{2}$ Central Department of Zoology, Tribhuvan University, Kirtipur, Kathmandu, Nepal \\ bishokd@gmail.com
}

\begin{abstract}
Presence of the red panda was assessed in Rachuli Village Development Committee (VDC)

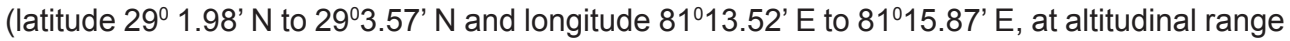
between 1800 to 4400 masl), Kalikot, mid-west Nepal. The interaction and interviews with local peoples was organised to collect initial confirmation on occurrence of the red panda. For sign survey of animal, altogether 20 quadrate plots (each of $10 \times 10$ sq. meters) at the point where pellets of red panda were found, were laid between altitude of $2800 \mathrm{~m}$ to 3300 masl. The presence of Red panda pellets in the study area was major evidence of presence of red panda in the area. The lowest altitude in which pellet found was $2993 \mathrm{~m}$ and the highest was $3297 \mathrm{~m}$. The highest number of pellets was observed in altitudinal range of $3100 \mathrm{~m}$ to 3150 $\mathrm{m}$. The average number of pellets per group was $10.13 \pm 5.33$. The typical dominant species of trees in red panda habitat were Betula utilis, Abies spectabilis and Quercus semecarpifolia observed with the highest Important Value Index (IVI) of 83.80, 75.83 and 52.80 respectively. Nigalo (Thamnocalamus sp.), the most preferable food plant of red panda, was distributed widely in the study range. The number of pellets groups in the plots and nigalo density were positively correlated $(0.795$, significant statistically at 0.01 levels (2-tailed)).
\end{abstract}

Keywords: red panda, forest, important value index, pellets

\section{INTRODUCTION}

Two sub-species of Red panda Ailurus fulgens fulgens and Ailurus fulgens styani are distributed from the Himalayan region of India to Nepal, China, Bhutan, Myanmar and Laos. Only Ailurus fulgens fulgens is found in Nepal (Chalise, 2009). This species prefers bamboo/ nigalo or Fir-bamboo/nigalo orest between 2500 m and 4000 m (Yonzon \& Hunter, 1991; Paudel, 2009; RPNN, 2010; Panthi et al., 2012). Recently, it has been reported that red panda can be found above $1500 \mathrm{~m}$ of elevation in Nepal (Chalise, 2009).

Basnet et al. (2012) confirmed red panda habitat ranges up to $592 \mathrm{sq}$. km while the extent of the potential Red panda habitat measures up to 2,653 sq. $\mathrm{km}$ in Nepal. The confirmed red panda habitat has been identified to be distributed among 11 subpopulation areas comprising of Kanchanjungha-Ilam Complex, Sankhuwasabha East, Sankhuwasabha West, Sagarmatha, Gaurishankar, Langtang, Annapurna-Manaslu Complex, Dhorpatan, Rara, Api Nampa, and Khaptad subpopulation. The metapopulation was likely to hold roughly between 230 to 1,060 individuals. These 11 subpopulations were clumped into six population complexes distributed 
over three regions- East, Central and West. Kalikot district lies in Rara subpopulation group (Basnet et al., 2012).

The red panda is protected by the National Parks and Wildlife Conservation (NPWC) Act 1973 of Nepal. It is in endangered category of International Union for Nature Conservation (IUCN) Red List where as it is listed in Appendix I of CITES. Its conservation status is Vulnerable C1 ver 3.1 and population trend is decreasing (IUCN, 2012). This research was focused on primary confirmation of red panda presence in Rachuli VDC of Kalikot District, Nepal. Research area is virgin area in terms of research of red panda and its conservation activities.

\section{MATERIALS AND METHODS}

\section{Study area}

The study area was at Rachuli VDC that lies in Kalikot District of Nepal. The area of the VDC is 63.257 sq. km and extends from latitude of 2901.98' $\mathrm{N}$ to $29^{\circ} 3.57^{\prime} \mathrm{N}$ and longitude of 81013.52' $\mathrm{E}$ to $81^{0} 15.87^{\prime} \mathrm{E}$ with altitudinal range of $1800 \mathrm{~m}$ to $4400 \mathrm{~m}$. Rachuli VDC is broadly divided into Northern and Southern parts by Tila Karnali river. The study area lies in temperate monsoon climatic zone. With reference to weather station Jumla, the mean normal temperature of the area is $12.83\left(-5^{\circ} \mathrm{C}\right.$ to $\left.26^{\circ} \mathrm{C}\right)$. The mean annual rainfall in the area is recorded $811.4 \mathrm{~mm}$ (DHM, 2013). The area indicated characteristics o2f upper temperate forests phytologically. The major species of trees found in the area are Betula utilis, Abies spectabilis, Quercus semicarpifolia, Picea smithiana, Acer caesium, Prunus sp., Castanopsis indica, Juglans regia, Taxus bacata, Populus ciliate, Aesculus indica, Carpus uniminea, Rhododendron sp. and so on. Nigalo (Thamnocalamus sp.) is major subsurface cover in the forest in the study range. Deodar (Cedrus deodara) forest is major vegetation cover in the lower range of the VDC. This study was conducted in southern part of Rachuli VDC between altitudinal range of $2800 \mathrm{~m}$ and $3300 \mathrm{~m}$ during 26th April to 2nd May 2013.

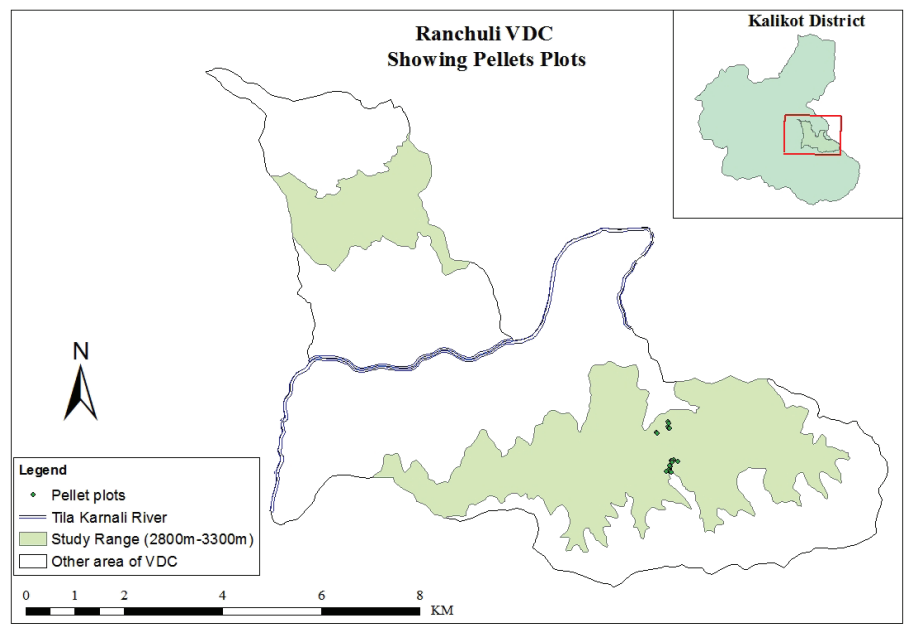

FIG. 1. Ranchuli VDC, Kalikot district (study area). 
In present study questionnaire survey was conducted among 33 households of southern region of Ranchuli VDC for confirmation of occurrence of red panda and to know location of probable habitat. Questionnaire survey was conducted. Photographs of red panda and its pellets were shown for recognition of red panda and its pellets.

Sign/pellets survey was carried out in order to confirm the presence and to analyse distribution of Red Panda. Pellets of red panda were searched between $2800 \mathrm{~m}$ to $3300 \mathrm{~m}$ and quadrat plot of $10 \times 10 \mathrm{~m}^{2}$ were laid where pellets were found. Altogether 20 plots were surveyed and latitude, longitude and altitude of the plots were recorded using Garmin Etrex Vista® GPS. Number and group number of pellets of red panda and the number, diameter at breast height $(\mathrm{DBH})$ and height of trees occurred on the plots were recorded in checklists. For vegetation analysis, Importance Value Index (IVI) was calculated using formula as:

$\mathrm{IVI}=$ Relative density + Relative frequency + Relative coverage

The Pearson correlation between pellets group and nigalo density was calculated using SPSS 16.0 software. One-Sample Kolmogorov-Smirnov Test using SPSS 16.0 software was done for testing normal distribution of nigalo density and pellets density.

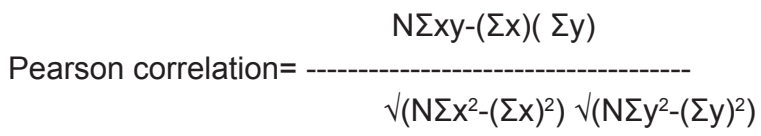

where, $x=$ pellets group number, $y=$ nigalo density, $N=$ number of plots

\section{RESULTS AND DISCUSSION}

Informal interviews with District Forest Officer and inhabitants of Kalikot district had revealed that along with Ranchuli VDC, the potential VDCs for red panda habitat were Chilkhaya, Odonaku, Gela, Mugraha, Sukatiya and Bharta, Khina and Thirpu. The survey also indicated that $36.36 \%$ of total respondents had seen red panda individual directly in the forest or vicinity of forest and $48.48 \%$ of respondents had observed its pellets (fig. 2). The red panda and its pellets were observed in various places such as steep slope, trees holes, cave, Nigalo bushes and vicinity of river. the red panda was called by different local names such as Naututo, Nigali Baag which was revealed from informal discussion with people in Ranchuli VDC. Besides, this animal was less familiar to people of Kalikot district. 


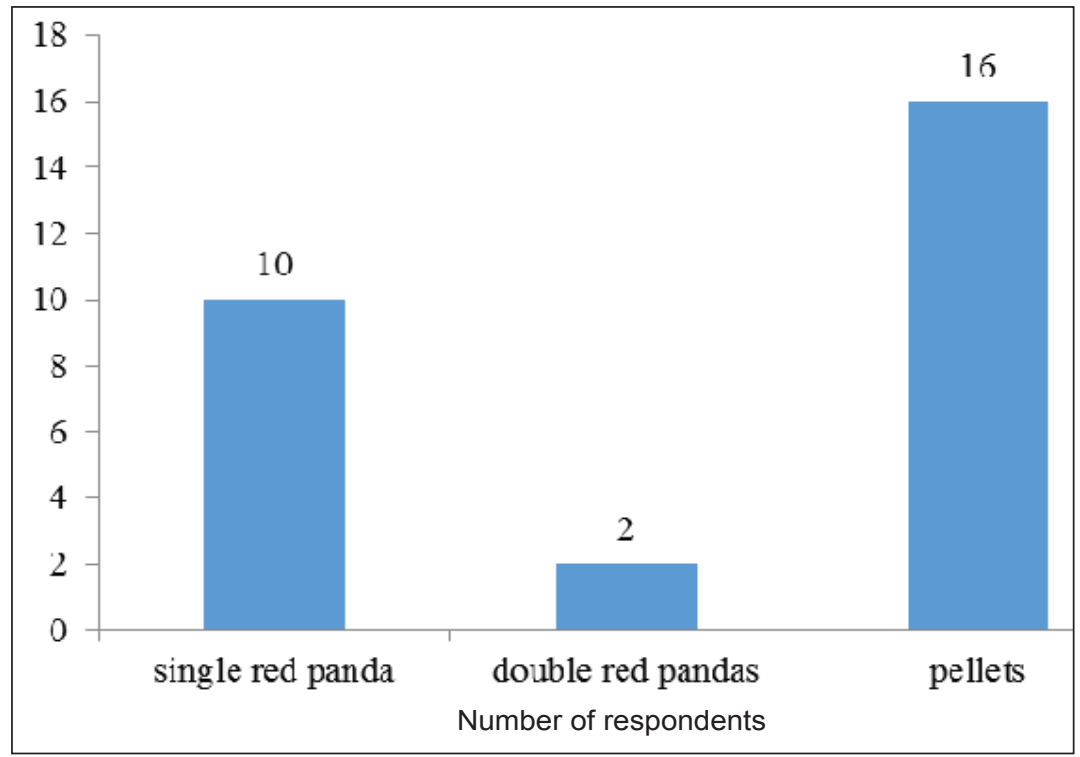

FIG. 2. Observations of red panda by respondents.

The dominant species of trees in the observed plots were Betula utilis, Abies spectabilis, Quercus semecarpifolia, Prunus sp., Acer caesium, Populus ciliata with IVI value of 83.80, 75.83, 52.80, 13.77, 9.68, 6.79 respectively (fig. 3).

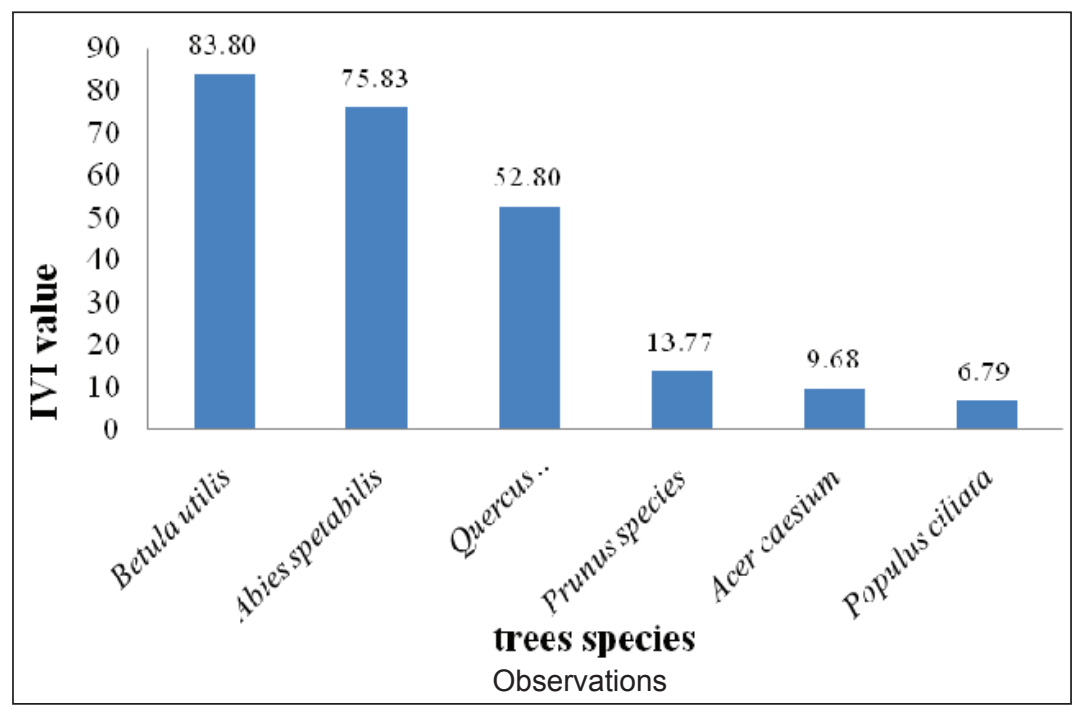

FIG. 3. IVI of trees in pellets of red panda presented plots.

As shown in fig., the average nigalo density in the plots was 1.13 per sq. meter. The highest nigalo density observed was 5.56 per sq. meter in a plot at an altitude of $3100 \mathrm{~m}$ amsl. 


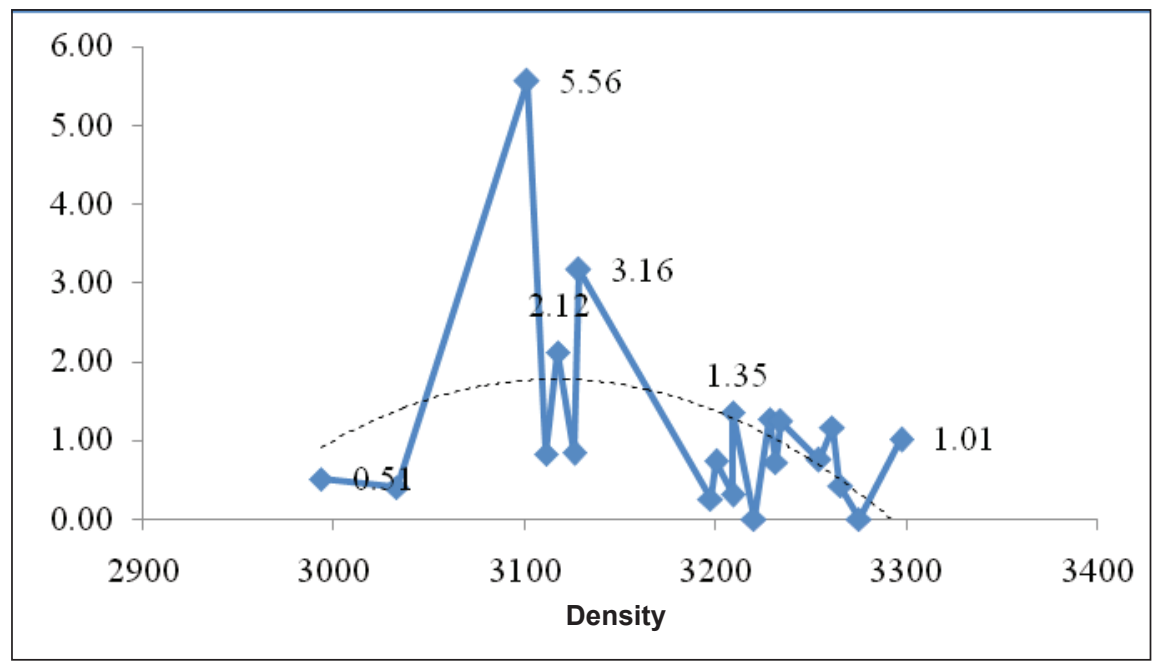

FIG. 4. Nigalo density in pellets of red panda observed in the plots.

Pellets sign were important evidence for the presence of red panda in the study area. Red Panda pellets were found between the altitudes of $2993 \mathrm{~m}$ to $3297 \mathrm{~m}$ amsl in the study area.

In 20 quadrats, 39 pellet groups was observed. The highest number of pellet groups was observed between the range of $3100 \mathrm{~m}$ to $3150 \mathrm{~m}$ (18 groups of pellets) which was followed by altitudinal range of 3200-3250 m and 3250-3300 m with pellet group number of 9 and 8 respectively (fig. 5). The average number of pellets in a group was found to be $10.13 \pm$ 5.332. Most of pellets were dark green and intact. Pellets were mostly found underneath trees/ malingo/nigalo on fallen logs, cave like structure

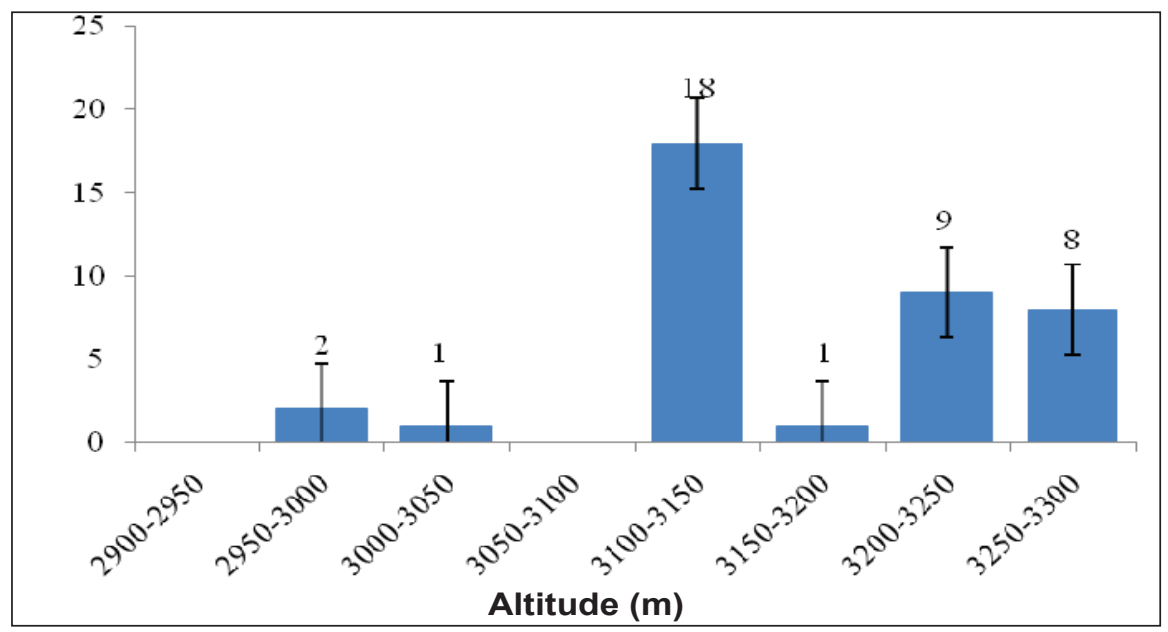

FIG. 5. Distribution of pellet groups according to altitudes. 
The One-Sample Kolmogorov-Smirnov Test showed that nigalo density and pellet density were normally distributed (table 1). The Pearson correlation between number of pellets groups and nigalo density was about 0.795 which was significant statistically at 0.01 levels (table 2 ).

TABLE 1. Result of one-sample Kolmogorov-Smirnov Test.

\begin{tabular}{|l|l|l|l|}
\hline \multicolumn{2}{|c|}{ Plot number } & \multicolumn{1}{|c|}{ Pellets group } & \multicolumn{1}{c|}{ Nigalo density } \\
\cline { 3 - 4 } & \multicolumn{1}{|c|}{20} & \multicolumn{1}{c|}{20} \\
\hline \multirow{2}{*}{ Normal parameters ${ }^{\mathrm{a}}$} & Mean & 1.95 & 1.1305 \\
\cline { 2 - 4 } & Std. Deviation & 2.685 & 1.27531 \\
\hline \multirow{3}{*}{ Most extreme differences } & Absolute & .362 & .282 \\
\cline { 2 - 4 } & Positive & .343 & .282 \\
\cline { 2 - 4 } & Negative & -.362 & -.188 \\
\hline Kolmogorov-Smirnov Z & 1.618 & 1.260 \\
\hline Asymp. Sig. (2-tailed) & .011 & .084 \\
\hline a Test distribution is normal. & & \\
\hline
\end{tabular}

TABLE 2. Correlation of pellet groups and Nigalo bamboo density.

\begin{tabular}{|l|l|l|l|}
\hline & & Pellets groups & Nigalo density \\
\hline \multirow{4}{*}{ Pellets Groups } & Pearson correlation & 1 & $0.795^{* *}$ \\
\cline { 2 - 4 } & Sig. (2-tailed) & & 0.000 \\
\cline { 2 - 4 } & $\mathrm{N}$ & 20 & 20 \\
\hline \multirow{3}{*}{ Nigalo Density } & Pearson correlation & $0.795^{* *}$ & 1 \\
\cline { 2 - 4 } & Sig. (2-tailed) & 0.000 & 20 \\
\cline { 2 - 4 } & $\mathrm{N}$ & 20 & 20 \\
\hline
\end{tabular}

${ }^{* *}$ Correlation is significant at the 0.01 level (2-tailed).

In the study area, typical dominant species of trees in red panda habitat, Betula utilis, Abies spectabilis and Quercus semecarpifolia were observed with highest Important Value Index (IVI) of 83.80, 75.83 and 52.80 respectively. Baral (2014) in Jajarkot District, the adjoining district of Kalikot, also found Abies spectabilis, Acer caesium, Quercus semecarpifolia, and Tsuga dumosa as major tree species in red panda habitat. Thamnocalamus sp. was the dominant nigalo species. The average nigalo density in pellet present plots was 1.13 per sq. meter. The highest nigalo density observed was 5.56 per sq. meter in an altitude of $3100 \mathrm{~m}$ amsl. Red panda were habitat specialists that preferred fir-bamboo forests between 2800 and 3900 m (Yonzon \& Hunter, 1991). Higher bamboo cover, bamboo height and canopy cover emerged as important habitat components in sites used by red panda (Animal centred plots) compared to random plots (Pradhan et al., 2001). Abies spectabilis was the most dominant tree in Riya Samba and Lama Khanak Forests of Kanchenjunga Conseravation Area with IVI of $62.46 \& 95.79$ respectively (Mahato \& Karki, 2005). 
Pellets of red panda is the major evidence of its occurence in the study area. In Rachuli Kalikot, red panda pellets were found between the altitudes ranged from $2900 \mathrm{~m}$ to 3300 $\mathrm{m}$. Altogether 20 spots were confirmed the presence of red panda pellets and 39 pellets groups was observed in the area. The highest number of pellet groups was observed between the altitudinal range of $3100 \mathrm{~m}$ to $3150 \mathrm{~m}$ (18 groups of pellets), which was at least two latrine site of red panda. The study by Bhatta (2014) in Jumla, the adjoining district of Kalikot, observed average number of pellets per pellet group was 12. In the study at eastern region of Nepal, distribution of red panda sign indicated that red panda found to be relatively more abundant in the $2,600 \mathrm{~m}-3,000 \mathrm{~m}$ range and that they are most dense in the $2800 \mathrm{~m}$ to 3000 $\mathrm{m}$ range (Williams, 2006). In Dhorpatan Hunting Reserve Nepal, red panda pellet groups were observed between the altitude $3000 \mathrm{~m}$ to $3600 \mathrm{~m}$ where frequency of pellet groups increased markedly from $3000 \mathrm{~m}$ to $3500 \mathrm{~m}$ and then declined sharply at higher elevations (Sharma \& Belant, 2009).

Another indirect evidence of the occurrence of red panda in the present study area was prevalence of nigalo (Thamnocalamus sp.), which is considered as one of the major food species. The average nigalo density in pellet present plots was 1.13 per sq. meter with the highest nigalo density observed in an altitude of $3100 \mathrm{~m}$.

In Langtang National Park, leaves of a single bamboo species, Jhapra (probably HimalayaCalamus falconeri) comprised $54-100 \%$ of the diet seasonally, with bamboo shoots, Sorbus fruits and mushrooms (Yonzon \& Hunter, 1991). The red panda diet consisted chiefly of bamboo leaves and species of bamboo, Arundinaria maling and A. aristata predominantly present as understorey in Singhalila National Park, however, the composition of diet differed with place (Pradhan et al., 2001). In another study carried out by Sharma (2012) around Rara National Park Nepal, that highest plant fragment of Thamnocalamus sp. was found in both pre monsoon and post monsoon period by diet composition analysis. Other major components were Abies, Rhododendron, Quercus, Betula, Tsuga, Taxus and Acer. The seed components of Aconogonum, Juniperus, Sorbus and mushroom components were found in less amount.

The Pearson correlation between pellets group and nigalo density was about 0.795 which was statistically significant at 0.01 levels showing highly correlated to pellets groups found in the plot and nigalo density.

The evidence of the red panda found in the area was one the western most region in the world. No scientific study has confirmed the presence of red panda further west of the area. However in farwestern region, some droppings were doubtfully collected but the size and shape did not match as of previous eastern samples and the local peoples recorded up to red 9-10 pandas which were enlisted for Rapla and Siddhinath forests in the Api Nampa Conservation Area (ANCA) (Chalise, 2014).

\section{ACKNOWLEDGEMENTS}

We would like to express our heartfelt gratitude to Prof. Dr. Kedar Rijal, Head of Department, Central Department of Environmental Science (CDES), Tribhuvan University (TU) Kirtipur, Kathmandu for his initiation, inspiration and continuous co-operation for conducting this study. This gratitude also goes to Red Panda Network (RPN) for providing fund for conduction of 
the study. Thanks also go to Mr. Dhan Bahadur Bohara who had given incredible time in field and for helping in field work. We would like to thank all the people of Rachuli VDC and Kalikot district for assisting directly and indirectly in this research.

\section{REFERENCES}

BARAL, B (2014) Baseline study of red panda (Ailurus fulgens fulgens CUVIER, 1825) in Jajarkot district, mid-western Nepal. M.Sc. Thesis, Central Department of Environmental Science, Tribhuvan University, Kirtipur, Kathmandu, Nepal.

BHATTA, M; SHAH, K B; DEVKOTA, B; PAUDEL, R; PANTHI, S (2014) Distribution and habitat preference of red panda (Ailurus fulgens fulgens) in Jumla district, Nepal. Open Journal of Ecology 4:989-1001. Available at $h$ ttp://dx.doi.org/10.4236/oje.2014.415082.

CHALISE, M K (2009) Observation of red panda (Ailurus fulgens) in Choyatar, Ilam, east Nepal. Journal of Natural History Museum 24: 97-103.

CHALISE, M K; THAGUNNA, S S (2014) Red panda in Api Nampa Conservation Area, Darchula, Nepal. DNPWC Special edition by Department of National Parks and Wildlife Conservation,Kathmandu, Nepal; pp 113-123.

IUCN (2012) IUCN Red list of threatened species version 2012.1. Available at www.iucnredlist.org.

MAHATO, N K; KARKI, J B (2005) Distribution and habitat assessment of red panda (Ailurus fulgens) in Kanchenjunga Conseravation Area with reference to Riya Samba and Lama Khanak forests. Nepal Journal of Forestry 12(3): 32-40.

PANTHI, S; ARYAL, A; RAUBENHEIMER, D; LORD, J; ADHIKARI, B (2012) Summer diet and distribution of the red panda (Ailurus fulgens fulgens) in Dhorpatan Hunting Reserve, Nepal. Zoological Studies 51(5): 701-709.

PAUDEL, K N (2009) Status and distribution of red panda (Ailurus fulgens) in Manang district, Nepal. Unpublished B.Sc. Thesis, Tribhuvan University, Institute of Forestry, Pokhara Campus, Pokhara Nepal.

PRADHAN, S; SAHA, G K; KHAN, J A (2001) Ecology of the red panda Ailurus fulgens in the Singhalila National Park, Darjeeling, India. Biological Conservation 98(1):11-18.

RPNN (2010) Study on ecology, behaviour and conservation of red panda in the sacred Himalaya Landscape (SHL) of Nepal. Report by Red Panda Network Nepal.

SHARMA, H P; BELANT, J L (2009) Distribution and observations of red pandas Ailurus fulgens fulgens in Dhorpatan Hunting Reserve. Nepal Small Carnivore Conservation 40: 33-35.

SHARMA, H P (2012) Exploration and diet analysis of red panda (Ailurus fulgens) for its conservation in Rara National Park, Nepal. Rufford Small Grants Foundation, UK.

WILLIAMS, B H (2006) Red panda in eastern Nepal: How do they fit into ecoregional conservation of the eastern Himalaya. In MCNEELY, J A; MCCARTHY, T M; SMITH, A; OLSVIG-WHITTAKER, L; WIKRAMANAYAKE, E D (eds) Conservation biology in Asia. Society for Conservation Biology Asia Section and Resources Himalaya, Kathmandu, Nepal; pp 236-251.

YONZON, P B; HUNTER, JR. M L (1991) Conservation of the red panda Ailurus fulgens. Biological Conservation 57:1-11. Available at http://dx.doi.org/10.1016/0006-3207(91)90104-H. 